VERLAUFSKONTROLLE BEI PARKINSON

\section{Zeichnung als Zittersensor}

- Aus einfachen Zeichnungen von Parkinsonpatienten lassen sich der Verlauf der Krankheit sowie die Wirksamkeit der Behandlung ablesen. Mit einem Computerprogramm ermitteln Wissenschaftler der Ruhr-Universität Bochum die Tremoramplitude, ein direktes Maß für die Stärke des Händezitterns beim Zeichnen.

Nun soll der erste Parkinsontest für zu Hause entwickelt werden, um die Symptome über längere Zeit unter Alltagsbedingungen zu verfolgen. Bewährt sich die Methode, könnte sie in der Hausarztpraxis später auch als Screeninginstrument eingesetzt werden, so der Leiter der Studie, PD Dr. Peter H. Kraus. Die Probanden zeichnen an vier Tagen einer Woche stündlich eine Spirale sowohl mit der rechten als auch mit der linken Hand auf einen Vordruck. Zusätzlich notierte Informationen zum Allgemeinbefinden sollen zeigen, wie die Selbsteinschätzung der Patienten mit der Computerauswertung übereinstimmt und was sich im Tagesverlauf bzw. durch die Medikamenteneinnahme verändert.

An der Studie teilnehmen können alle Patienten mit diagnostizierter Parkinsonerkrankung. Die Unterlagen sind kostenlos über das Parkinson-Informations-Telefon unter 01805/191909 zu beziehen.

ST =
Stechmücken der Gattung Culex können das SindbisVirus übertragen.

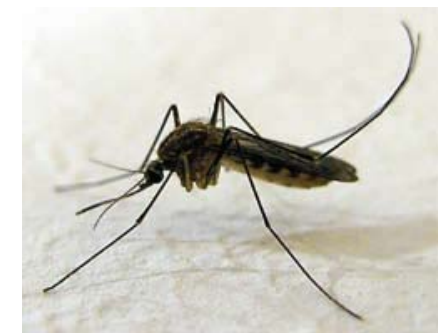

NEUES VIRUS IN DEUTSCHLAND

Rheumabeschwerden nach Mückenstich

- Forscher des Bernhard-Nocht-Instituts (BNI) für Tropenmedizin haben entdeckt, dass in Deutschland Sindbis-Viren zirkulieren. Die Viren wurden in drei Mückenarten nachgewiesen. Das Virus stammt ursprünglich aus Afrika, kommt aber seit einigen Jahren auch in Europa vor, besonders in Schweden und Finnland. Werden die Viren durch einen Mückenstich auf Menschen übertragen, können sie fieberhafte Erkrankungen auslösen, die häufig mit Entzündungen der Gelenke einhergehen und daher rheumatischen Beschwerden ähneln. „Normalerweise befallen Sindbis-Viren Vögel. Obwohl eine Einschleppung durch Vogelzug vermutet werden konnte, wurden sie bisher in Deutschland nicht gefunden“, sagte Dr. Jonas Schmidt-Chanasit vom BNI. Die Arbeitsgruppe um den Virologen bietet medizinischem Fachpersonal Informationsmaterial und kostenlose Diagnostik von Patientenproben an (E-Mail: schmidt-chanasit@bnitm.de). BS . Pressemeldung des BNI, 3. Mai 2010

\title{
Ernährungsberater Evo Morales
}

Bei der "Weltkonferenz der Völker über den Klimawandel und die Rechte der Mutter Erde“ in Tiquipaya nutzte Evo Morales, der Präsident Boliviens, die Gunst der Stunde, um seine bahnbrechenden Erkenntnisse unters internationale Volk zu streuen. Wir müssen uns zwischen dem Kapitalismus und Mutter Erde entscheiden, so seine Botschaft. Siegt der Kapitalismus, stirbt Mutter Erde. Die Mordinstrumente hat er auch gleich ausgemacht: Plastik, genmanipulierte Lebensmittel, Coca-Cola und hormongemästete Hühnchen. Die Teilnehmer der Konferenz starrten verlegen auf die Plastikteller, auf denen man ihnen einen Imbiss serviert hatte.

Ein Klempner, der eine Rohrverstopfung mit handelsüblichen Reinigern nicht lösen konnte, habe schließlich mit Coca-Cola Erfolg gehabt, wusste Morales zu berichten. Genmanipulierte Lebensmittel, insbesondere die holländischen Kartoffeln, seien dafür verantwortlich, dass praktisch alle Europäer kahlköpfig seien. Morales führte seinen dichten Haarschopf darauf zurück, dass er nie holländische Kartoffeln gegessen habe. In 50 Jahren, so unkte der Präsident, werde die ganze Welt kahlköpfig sein. Wenn er Recht hat, sollte man schleunigst in holländische Kartoffeln investieren. Scheinen eine große Zukunft zu haben die Dinger.

Der schlimmste Auswuchs des Kapitalismus sind laut Morales hormongemästete Hühner. Männer, die davon essen, würden von ihrer Männlichkeit abweichen, oder kurz: Huhn macht schwul. In der spanischen Zei- tung „El Pais“ meldeten sich homosexuelle Vegetarier zu Wort, die sich wunderten, woher dann wohl ihre „Abweichung“ kommen könne.

Ein Ergänzungsvorschlag, um das Wohl von Mutter Erde zu retten, kommt von dem iranischen Kleriker Hojatolesdam Sedighi. Frauen, die sich aufreizend kleiden, seien schuld an den häufigen Erdbeben, predigt Sedighi. Aus Protest verabredeten sich Frauen weltweit zum „Boobquake Event", um an diesem Tag so viel Haut wie möglich zu zeigen. Hat der Geistliche recht, droht der Weltuntergang. Liegt er falsch, haben die Männer, die nicht durch hormongemästete Hühner verdorben sind, mal wieder richtig was zum Gucken.

REINHOLD MANHART - 